\title{
INDIFERENCIA, AMBIVALENCIA Y TIPOS DE CONSENTIMIENTO. AGUSTÍN EN EL SCITO TE IPSUM DE ABELARDO ${ }^{1}$
}

\author{
Manfred Svensson* \\ msvensson@uandes.cl
}

RESUMEN Agustín y Abelardo son frecuentemente puestos como modelos antagónicos de una ética de absolutos morales y una centrada en la intención. El presente artículo enfatiza más bien la coincidencia de ambos en dichos puntos, para defender en cambio que difieren en el tipo de acto interior decisivo para la evaluación moral y en la indiferencia o ambivalencia atribuida al acto exterior.

Palabras clave Agustín, Abelardo, consentimiento, intención, indiferencia, ambivalencia.

ABSTRACT Augustine and Abelard are frequently portrayed as representing mutually exclusive models of ethical theory: one centered in absolute moral norms, the other in intention. The present article stresses rather their agreement in these issues, while pointing to other differences between them: the kind of interior act each of them considers decisive, and the description of the external act as indifferent or ambivalent.

Keywords Augustine, Abelard, consent, intention, indifference, ambivalence.

* Professor de Filosofia, membro do Grupo de Investigación en Filosofía Práctica do Instituto de Filosofía da Universidad de los Andes. Artigo recebido em 19/1/2011 e aprovado em 4/6/2011.

1 El presente trabajo es parte de una investigación financiada por el Fondo Nacional de Desarrollo Científico y Tecnológico, FONDECYT, proyecto № 11090189 "La distinción entre cosas indiferentes (adiaphora) y necesarias: un paradigma de la modernidad temprana en la obra de Melanchthon y Locke".

KRITERION, Belo Horizonte, no 125, Jun./2012, p. 103-118. 


\section{Introducción}

"Llamamos propiamente pecado al consentimiento"2. Esta tesis de Abelardo se acostumbra estudiar con la mirada puesta en el mismo Abelardo o bien con la mirada puesta en los desarrollos a los que dio origen; esto es, o bien se vincula con su propia agitada biografía y producción -el énfasis en la intención como factor principal de la evaluación moral podría enmarcarse entonces en su relación con Eloísa- , o bien se le estudia para ver cómo sus radicales tesis operan como catalizadoras de la abundante discusión del siglo siguiente sobre la especificación del acto moral. En cualquiera de los dos casos su tesis principal parece vincularse a todos los grandes temas de su propia obra y del pensamiento del período. En palabras de Chenu, Abelardo "proclamó la primacía de la intención como lo que determina tanto un acto bueno como un pecado, y estableció así la primacía del juicio de la propia conciencia, sin el cual el acto no existiría. De ahí se siguió también la importancia de la contrición en el sacramento de la penitencia, con la absolución degradada a mera palabra de despedida; y de ahí se siguió también su noción de pecado original, en la que por la ausencia de una voluntad personal queda también eliminada la culpa propiamente tal. De ahí también su actitud antiaugustiniana respecto de la naturalidad del placer sexual, el que sólo puede ser contaminado por una intención errónea"3. Nos tomamos de estas últimas palabras de Chenu sobre Abelardo -su eventual actitud antiaugustiniana- para plantear una aproximación a su obra distinta de las dos que hemos mencionado: no dirigimos la mirada a la biografía de Abelardo ni a las discusiones que suscitaría su obra, sino hacia atrás, para analizar la presencia de Agustín en la obra del Palatino y ver qué nos dice dicho contraste respecto de las tesis principales de ambos.

Que tal presencia es significativa apenas requiere ser mencionado: en su Dialogus inter Philosophum, Iudaeum et Christianum Abelardo hace que el filósofo remita al cristiano a la obra de Agustín, dirigiéndole las siguientes palabras: "como dice vuestro máximo filósofo"... ${ }^{4}$ Y lo que Agustín dice ahí, citado por el filósofo, es que sólo el amor permite distinguir a los hijos de Dios

2 ABELARDO, Pedro. Scito te Ipsum I, 3, 2. Me sirvo de la edición de Rainer llgner en Turnhout: Brepols, 2001. Los distintos editores y traductores de Abelardo no presentan acuerdo en el modo de dividir el texto. Sin entrar en dicha discusión, en el presente artículo sigo la división propuesta en la edición de llgner.

3 CHENU, M-D. Nature, Man, and Society in the Twelfth Century Toronto: University of Toronto Press, 1997. p. 284.

4 ABELARDO. Collationes II, 99 (ed. MARENBON, J; ORLANDI, G. Collationes Oxford: Oxford University Press, 2001). Esta proximidad a Agustín resulta tanto más enfática si se considera el contraste con Boecio. A pesar de estar escribiendo en una "aetas boethiana", Abelardo escribe de Boecio que "quamuis Christianus opinionem secutus philosophorum, cum de philosophia tractaret”. Theologia Christiana 3, 122 (Opera Theologica Petri Abelardi II, Turnhout: Brepols 1969-). 
de los hijos del diablo. Quedamos así situados ante una tesis característicamente agustiniana y abelardiana: la centralidad del amor o la intención como el factor decisivo para la evaluación moral. Pero el locus classicus de tal tesis no es el Dialogus de Abelardo, sino su Scito te Ipsum. Lo que a continuación me propongo es pues revisar con atención la presencia de Agustín en dicha obra. Por tal presencia se puede preguntar de distintos modos y en diversos niveles: se puede preguntar por la general conformidad entre las tesis de Abelardo y las de Agustín, se puede intentar un análisis de los textos agustinianos directa $\mathrm{o}$ indirectamente referidos por Abelardo, se puede preguntar por los textos de Agustín de los que Abelardo no parece tener noticia, y se puede también preguntar por el uso que ambos hacen de unos mismos textos bíblicos para exponer y fundamentar sus posiciones. En este estudio me centraré en las primeras dos preguntas de esta lista: la compatibilidad entre las tesis de ambos y el uso de Agustín como fuente.

¿Pero qué interés puede tener esta pregunta por la presencia de Agustín en la obra de Abelardo? Lo tiene en primer lugar por la cantidad de autores que ven en Agustín, en Abelardo o en ambos, por su énfasis en la interioridad, un impulso hacia una ética específicamente cristiana ${ }^{5}$. Si un estudio detenido arroja por resultado que enfatizan la interioridad de un modo muy distinto, también la pregunta por esta especificidad tiene que plantearse de un modo más diferenciado. En segundo lugar, la cuestión es también históricamente interesante porque cuando Pedro Lombardo presenta en las Sentencias la tesis central de Abelardo, "que todo acto es bueno por una intención buena o malo por una intención mala"6, el mismo Lombardo responde con una cita de Agustín, en la que éste concuerda con la tesis de Abelardo, pero de un modo parcial: importa mucho cuál es la intención con que se hace algo, pero hay cosas que es imposible hacer con buena intención ${ }^{7}$. Así, hasta el día de hoy nos encontramos con contraposiciones entre Abelardo como un representante de una moral basada en la sola intención y Agustín como alguien que, no obstante dar a la misma un papel importante, reconoce también ciertas normas morales carentes

5 Al comenzar el segundo libro del Scito te Ipsum, Abelardo usa la expresión "ethica nostra" (II, 1, 1). ILGNER, R. "Scito te Ipsum-Ethica nostra. Zu Herkunft und Bedeutung des Titels von Abaelards Ethik", Theologie und Philosophie 76, 2001, pp.253-270 ha demostrado de modo convincente que si bien sólo Scito te Ipsum (y no Ethica) debe ser entendido como título de la obra, la expresión ethica nostra da clara cuenta de un intento por analizar la ética con herramientas filosóficas pero con una intención específicamente cristiana. La misma especificidad sostiene respecto de Agustín PINCKAERS, S. Las Fuentes de la Moral Cristiana Pamplona: Eunsa, 1988. p. 222.

6 LOMBARDO. Sent. II, d. 40, 5. Sententiae in IV Libris Distinctae Grottaferrata: Spicilegium Bonaventurianum, 1971.

7 LOMBARDO. Sent. II, d.40, 7. Citando a Agustín Contra Mendacium 8, 17. 
de excepción ${ }^{8}$. Tal contraposición que Lombardo hace entre Abelardo y Agustín en dicho único punto, mostrando lo que tienen en común y lo que aparentemente los diferencia, es lo que aquí quiero extender a algunos puntos más.

\section{Las tesis centrales de Abelardo y su estrategia agustiniana}

Comenzaremos caracterizando en breves palabras el modo en que Abelardo nos introduce en su pensamiento moral. Su Scito te Ipsum parte muy concisamente excluyendo ciertos elementos: hay vicios del alma y del cuerpo, dice, pero sólo a los del alma los llamamos hábitos (mores); son éstos los que conducen a las opera. Pero también entre estos vicios y virtudes del alma hay algo que debe ser excluido: hay virtudes intelectuales, como la agudeza, que no necesariamente tienen efecto sobre la vida moral. Hechas tales precisiones se excluye algo más: el pecado no consiste en el vicio que inclina el alma al mal. Tal inclinación al mal sólo nos da ocasión para luchar; lo que debemos impedir es que en tal lucha demos el consentimiento. La tentación es de hecho analizada como un proceso tripartito de suggestio-delectatio-consensio, tentación-deleite-consentimiento, con el pecado haciendo su entrada sólo en esta última etapa. Con esto, que ya está dicho dentro de las primeras tres páginas de la obra, la tesis central de Abelardo ya está expuesta: el pecado es definido como consentimiento a la mala inclinación o desprecio a Dios, y a partir de ahí es devaluada la importancia de la realización externa de los actos: así como en la evaluación moral se excluye la torpeza corporal o la falta de agudeza intelectual, se excluye también la ejecución de la obra externa. Tal ejecución no añade mal, ya que éste se encuentra presente de modo completo en el consentimiento. Como éste es el único factor decisivo, incluso la distinción entre pecados veniales y mortales pasa a relacionarse no con alguna materia propia del acto, sino con tipos o grados de consentimiento.

¿Hay algo prima facie agustiniano en estas tesis? Antes de dirigir la mirada al tópico tal vez más importante, la centralidad del consentimiento, cabe mencionar que, sea cual sea la cercanía entre las tesis fundamentales de ambos autores, hay una estrategia agustiniana que Abelardo está siguiendo para llegar a sus tesis, esto es, el proceder descartando cosas que son comunes a los buenos y los malos. Ya en las primeras páginas de la obra Abelardo pone esto repetidas veces como criterio: las cosas que son comunes a buenos y malos -tener buena memoria o mucha ciencia- no son parte integrante de la 
moralidad, no guardan relación alguna con la virtud y el vicio9. Esto mismo se puede encontrar con frecuencia en Agustín, desde los tempranos diálogos de Casicíaco hasta la Ciudad de Dios: el hecho de que un bien sea común a buenos y malos muestra que el bien en cuestión es ambivalente: puede ser bueno, pero no nos hace buenos, y no es por tanto el tipo de bien que primordialmente debemos buscar ${ }^{10}$. Como tendremos ocasión de ver, esta estrategia común de ambos autores se encuentra con frecuencia en textos vinculados con las tesis centrales de los mismos. Se descarta lo común a buenos y malos para llegar a lo que sin ambivalencia alguna explique la bondad de los buenos y la maldad de los malos. Esta navaja avanza tal vez más rápido en manos de Abelardo que en manos de Agustín, pero es de éste que proviene.

\section{Abelardo y la primacía agustiniana de la intención}

Si dirigimos la mirada al resultado de dicho proceso, la presencia de Agustín en la obra de Abelardo vuelve a ser importante. Lo primero que merece ser mencionado es que las referencias explícitas de Abelardo a Agustín son todas con miras a la defensa de la tesis central de aquél. Comenzaremos comentando dichas referencias explícitas, para luego dirigirnos a textos relacionados con la explicación tripartita de la tentación y la distinción entre pecados veniales y mortales, puntos en los que Agustín está presente sólo en el trasfondo, pero de un modo igualmente claro.

En Scito te Ipsum hay cuatro ocasiones en que Abelardo presenta su tesis central invocando expresamente a Agustín como autoridad que avala su posición. Dos de éstas hablan de la intención como aquello en lo que cae todo el peso, las otras dos del amor como lo que desempeña el mismo papel. Paso en primer lugar a textos en que se menciona la intención o el consentimiento. De inmediato aparece la estrategia de apuntar a lo que es común a buenos y malos. Las obras que conviene hacer y las que no conviene hacer son igualmente hechas por buenos y por malos. Tanto Judas como Dios Padre, menciona Abelardo siguiendo explícitamente a Agustín ${ }^{11}$, entregan a Jesús. Pero no hay que mirar lo que se hace (quae fiunt), sino con qué disposición se hace (quo animo fiant); el mérito no está in opere, sino in intencione ${ }^{12}$. De los textos que estamos considerando, es en éste que Abelardo más fielmente sigue

9 ABELARDO. Scito te Ipsum I, 6, 4 y I, 2, 8.

10 AGUSTín. De civitate Dei. XX, 2 y De libero arbitrio II, 19, 50.

11 AGUSTín. In epistulam lohannis ad Parthos 4, 7.

12 ABELARDO. Scito te Ipsum I, 17, 3. 
a Agustín, apartándose de él sólo en alguna variación terminológica, pero no en la enseñanza central.

Abelardo invoca luego a Agustín no sólo para la tesis de la centralidad de la intención, sino también de modo explícito para uno de sus corolarios, esto es, que la obra externa no añade mal alguno a la intención ya mala, que incluso si somos sorprendidos in fraganti no hay aumento alguno del mal ${ }^{13}$. Abelardo no cita aquí textualmente, sino sólo escribe que esto es así "como lo menciona Agustín" (ut beatus Augustinus meminit). El texto aludido es de libero arbitrio I, 3, 8. Agustín se encuentra ahí en busca del origen del mal, y dice a Evodio que éste tal vez no lo está encontrando porque está buscando afuera, en el acto mismo que es malo, el cual salta a la vista (foris in ipso facto, quod iam videri potest), mientras que la libido es algo interno. Si alguien tuviera la intención de cometer adulterio, y lo haría si pudiese, será tenido por culpable tal como el que de hecho lo ha cometido (non minus reus est quam si in ipso facto deprehenderetur). En este punto tenemos que separar dos preguntas. Una es si acaso Agustín adhiere a la idea de la indiferencia del acto externo tal como la presenta Abelardo, una pregunta que tendremos que resolver más delante de la mano de otros textos. La segunda pregunta es si acaso el texto de Agustín al que alude Abelardo permite aclarar otras diferencias entre ambos. Pues Agustín sostiene dicha tesis en el marco de un ejemplo que Abelardo también discute, el caso de un esclavo que por temor a sufrir algún mal, acaba dando muerte a su $\mathrm{amo}^{14}$. El ejemplo es significativo en varios sentidos. En primer lugar, porque la imagen moderna de Abelardo como iconoclasta se viene abajo: al matar, escribe Abelardo sin sentimentalismo alguno, el esclavo da su consentimiento a la inclinación que tenía, de modo que ha pecado y no lo podemos absolver ${ }^{15}$. Pero más importante que eso es lo que a partir de aquí ha logrado mostrar Jean Porter. Para Agustín, en el ejemplo en discusión, el problema no se encuentra sólo en el consentimiento, sino en una inclinación desordenada, la libido, por la que se busca a toda costa mantener un bien temporal. Lo que hace Abelardo es adoptar el ejemplo y parte de la conclusión de Agustín, pero en su variante del ejemplo la pasión es neutralizada: el deseo de huir del mal amo no es malo, sólo es malo consentir a matar ${ }^{16}$. Lo que

13 ABELARDO. Scito te Ipsum I, 9, 8.

14 El aparato crítico de la última edición de llgner nos remite a dos lugares de la obra de Agustín: retr. I, 13, 5 y civ. I, 21. Pero estos textos en realidad sólo tratan del precepto de no matar y de las excepciones del mismo, sin nada que se asemeje al ejemplo en cuestión. Luscombe omite toda identificación de fuentes en este punto. En la dependencia respecto del de libero arbitrio coincido con PORTER, J. "Responsibility, Passion, and Sin. A Reassesment of Abelard's Ethics”, Journal of Religious Ethics, 28, 2000. p. 383.

15 ABELARDO. Scito te Ipsum I, 5, 6.

16 Véase el detenido análisis en PORTER, J. op cit. 383-388. 
Chenu presenta como una actitud "antiaugustiniana respecto de la naturalidad del placer sexual" es pues en realidad una tesis más general de Abelardo, no sobre la bondad de sólo ese placer, sino sobre la indiferencia de toda pasión. Incluso cabría hacer esto extensivo más allá de la pasión a cualquier acto interior distinto del consentimiento: "los mismos argumentos que Abelardo aplica a los actos externos para negar que sean pecados se aplican a los actos internos de pensamiento" 17 . Lo que entonces tenemos en Abelardo no es un vago énfasis en la interioridad -abarcando en ésta tanto la tendencia volitiva como el consentimiento a la misma-, sino una doble indiferencia que rodea al acto de consentimiento como lo exclusivamente decisivo: tanto la pasión que precede al consentimiento como el acto externo que le sigue son indiferentes. Sabemos que Agustín está en desacuerdo respecto del primer punto, y tendremos ocasión de ver más adelante lo que dice sobre el segundo.

Como señalamos hay dos pasajes más, en los que se expone esta misma doctrina, pero reemplazando "intención" por "amor". Lo primero que salta a la vista es que Abelardo invoca el célebre "ama y haz lo que quieras"18. No se trata de una cita literal, pues Abelardo varía significativamente los términos usados por Agustín, un buen indicio de lo proverbial que ya entonces parece haberse vuelto esta frase ${ }^{19}$. Son dos los textos de los que Abelardo podría haber sacado esta expresión: el comentario a la primera carta a Juan y el sermón 107. En el comentario de Agustín a la primera carta de Juan el tópico fundamental es que sólo en la raíz se distinguen los actos: hay cosas de apariencia buena, pero sin una raíz de caridad: "que la raíz sea el amor interior, escribe Agustín, de tal raíz no puede sino salir bien" ${ }^{20}$. En el sermón 107, en tanto, estamos en un contexto en el que esto coincide con la estrategia antes comentada: el amor es lo único que no es común a buenos y malos, y por eso es encomiado como el factor decisivo, que vuelve bueno todo lo ambivalente que hay en nosotros. Dos precisiones pueden ser necesarias en este punto. La primera precisión es que este énfasis en la intención o en el amor como únicos factores determinantes de la vida moral se encuentra en realidad en las antípodas de una relajación de las costumbres. La lectura romántica de tales textos puede ser descartada si recordamos que el célebre dictum agustiniano se encuentra en un sermón antidonatista. Como bien ha mostrado Gallay, el "ama y haz lo que quieras" es una recomendación a la autoridad política, un llamado a

17 HAUSE, J. "Abelard on Degrees of Sinfulness", American Catholic Philosophical Quarterly 81, 2, 2007. p. 256.

18 ABELARDO. Scito te Ipsum I, 24, 4.

19 Ilgner remite a s. 107, 4, Luscombe a la más clásica versión en el comentario a la primera carta de Juan. 20 AGUSTíN. In epistulam lohannis ad Parthos 7, 8. 
aplicar coerción desde la raíz del amor ${ }^{21}$. Y como bien ha revelado el ejemplo del esclavo discutido en el párrafo anterior, tampoco Abelardo está con esta teoría sosteniendo algo así como que "cualquier cosa que se haga con buena intención está bien". La segunda precisión tiene que ver con los respectivos énfasis en el amor o en la razón. Silvia Magnavacca ha sostenido que hay una fundamental unidad de Agustín y Abelardo, pero que difieren en este punto, por enfatizar Abelardo más la razón como el factor interior determinante y Agustín, en cambio, el amor ${ }^{22}$. Conviene, en efecto, notar tales diferencias, si bien en ambos hay cierta libertad terminológica, por la cual la tesis de la primacía del acto interior puede expresarse con ambas expresiones. Por lo demás, si bien la imprecisión al respecto es más riesgosa para el proyecto de Abelardo -pues él está intentando defender una marcada separación entre voluntas (como tendencia volitiva) y consensus (como decisión)- es Agustín quien con mayor frecuencia distingue, poniendo la intención y el amor en planos claramente distintos ${ }^{23}$.

Hechas estas precisiones podemos dirigirnos a la segunda referencia de Abelardo al amor como factor determinante, más reveladora que la primera: "También el bienaventurado Agustín, considerando esto diligentemente, reduce todo precepto o prohibición a la caridad o el deseo, más bien que a las obras"24. El texto de Agustín al que estas palabras remiten se encuentra en el De doctrina christiana y es citado por Abelardo del siguiente modo: "Nada ordena la ley sino la caritas y nada prohíbe sino la cupiditas". En el corpus agustiniano Abelardo podría haber encontrado muchos otros textos que se ajustarían mejor a su propio programa, pues éste texto parece sugerir precisamente que hay ciertos tipos de inclinación o deseo-cupiditas-que son pecado, y que éste no se encuentra por tanto sólo en el consentimiento. Además, de la mano de las mismas palabras, Agustín y Abelardo excluyen en realidad cosas distintas. Abelardo cita a Agustín diciendo que la ley sólo prescribe caridad, lo cual Abelardo contrapone a las obras. Pero lo que interesa a Agustín en el párrafo en cuestión no es un contraste con las obras en general, sino con nuestro apego a las meras costumbres locales como norma de conducta. Se trata de superar la estrechez que proviene de dicho criterio, y para eso la Escritura prescribe el amor y condena los malos deseos. Es de

21 GALLAY, J. "Dilige et quod vis fac, Notes d'exégèse augustinienne”, Recherches de science religieuse 43, 1955. pp. 545-555.

22 MAGNAVACCA, S. "<Vester Maximus Philosophus >: San Agustín en el Diálogo de Pedro Abelardo", Diadokhe 1-2, 2000. p. 65.

23 Las tal vez más elocuentes afirmaciones en ese sentido se encuentran en En. in Ps. 31, 4 y 5.

24 ABELARDO. Scito te Ipsum I, 16, 8. Sin énfasis en el original. 
este modo, escribe Agustín, que la Escritura "informa las costumbres de los hombres" 25 . El contraste con Abelardo es pues llamativo. Uno afirma que la ley se reduce al amor más bien que a las obras, el otro que debemos ser conducidos al amor para así informar las obras desde una perspectiva más rica que una mera costumbre.

¿Cómo evaluar entonces la apelación de Abelardo a la autoridad de Agustín en estas materias? Evidentemente hay sentidos en que tal apelación está plenamente justificada, y Abelardo podría haber encontrado textos de Agustín que apoyan incluso más decididamente las tesis en cuestión ${ }^{26}$. Al mismo tiempo, no obstante, han aparecido algunas grietas que pueden indicar diferencias entre ambos. Podríamos sintetizar esta diferencia diciendo que, partiendo de una misma estrategia, Abelardo enseña la indiferencia de lo externo, Agustín en tanto sólo su ambivalencia: para él un acto externo no es indiferente, pero tampoco revela la calidad moral del agente. Si dirigimos ahora la mirada a aquellos textos en que hay presencia de Agustín sólo de modo implícito, se expandirá tanto el tipo de estrategias que tienen en común como la brecha que separa a ambos autores.

\section{Pecado venial y mortal}

A continuación dirigiremos la mirada a dos elementos de la discusión abelardiana en los que Agustín no es explícitamente invocado. Agustín se encuentra en el trasfondo de los mismos, pero sus posiciones claramente difieren. Estos dos elementos que quiero examinar son, como ya he mencionado, la división tripartita del proceso de tentación y la distinción entre pecados veniales y mortales.

A esta distinción entre pecados veniales y mortales le dedicaremos sólo una consideración menor. Abelardo parece ponerla exclusivamente en un elemento subjetivo: llama veniales a ciertos pecados en los que incurrimos más por cierto olvido que deliberadamente, mientras que los pecados mortales son aquellos que son buscados de modo deliberado: se ejecutan ex studio et deliberacione ${ }^{27}$. Conviene, sin embargo, mencionar que en Abelardo esto parece de hecho coincidir con cierta delimitación a partir de la materia en cuestión. No es que cualquier cosa pueda ser hecha con liviandad y por tanto pueda ser calificada como pecado venial. El propio Abelardo nombra el perjurio, el

25 AGUSTín. De doctrina christiana. III, 10, 15.

26 Para un elenco representativo de textos véase MAGNAVACCA, S. "<Vester Maximus Philosophus > : San Agustín en el Diálogo de Pedro Abelardo", Diadokhe 1-2, 2000. p. 63-4.

27 ABELARDO. Scito te Ipsum I, 47, 8. 
adulterio y el homicidio como pecados por los cuales no se alcanza perdón con simplemente recitar "confieso a Dios y a vosotros, hermanos, que he pecado, etc." Estas cosas, y otras similares, son más graves y condenables, escribe, pues son cometidas buscándolas deliberadamente ${ }^{28}$. Abelardo no sostiene pues la tesis cruda que le atribuyó Pedro Lombardo al oponerlo a Agustín, sino la idea de que hay cierto tipo de actos cuya comisión necesariamente implica una deliberación más consciente: no asesinamos de modo superficial del modo en que hablamos demás con superficialidad. Con todo, sí es posible la transición en sentido inverso: hay una habladuría leve, superficial, que con tan sólo ponerle algo más de decidida intención puede llegar a volverse un pecado grave. Hay un deliberado amor al lujo que es distinto de haber sido algo superficial en el vestir. Las clases de pecado parecen así estar distinguidas por el tipo de consentimiento que se da, pero esto coincide con tipos de $\operatorname{actos}^{29}$; y dentro de eso se da la posibilidad de que el pecado venial cambie a mortal, pero no la de que el mortal cambie a venial. En Agustín, en cambio, es más frecuente que la distinción entre grados de pecado parta de tipos distintos de actos y no del tipo de consentimiento en cuestión. Pero tendremos que volver sobre esta distinción tras ver la tripartición de la tentación. Recién desde ahí se podrá ver qué ventajas decisivas parece tener la aproximación de Agustín al problema.

\section{El mecanismo psicológico de la tentación: suggestio-delectatio- consensio}

El punto que pasamos a considerar constituye un punto de singular fructificación recíproca de la tradición filosófica y la exégesis bíblica, pues se une aquí una exposición alegórica del Génesis con la reflexión sobre la secuencia representación-impulso-asentimiento. Recibimos una impresión, ésta conduce a un impulso, pero sólo en la medida en que le damos asentimiento se vuelve operativa para nuestra vida intelectual o nuestra vida práctica. El trasfondo sin duda es estoico, pero en la explicación estoica estamos ante una tripartición distinta. La psicología estoica de la acción presenta en primer lugar una representación (phantasía) que una vez representada de modo

28 ABELARDO. Scito te Ipsum I, 47, 4.

29 Aunque la interpretación contraria es la que seguimos encontrando en los manuales de historia de la filosofía y literatura general sobre el problema, la tesis que aquí sostenemos se encuentra ya firmemente establecida entre estudiosos de Abelardo. Como ejemplos representativos véase PORTER, J. op cit. y BEJCZY, I. "Deeds Without Value: Exploring a Weak Spot in Abelard's Ethics", Recherches de Théologie et Philosophie Médiévales 70, 1, 2003. pp 1-21. 
proposicional recibe o no el asentimiento (synkatáthesis), a lo cual sigue el impulso o movimiento (hormé). Es decir, es una tripartición que nos habla del impulso posterior al asentimiento, no del que lo precede. Pero dicha tripartición fue tempranamente utilizada para explicar el proceso de tentación a modo de interpretación alegórica del relato de la caída, aunque ahora incluyendo una hormé previa a la synkatáthesis. Los autores cristianos prestaron considerable atención a cómo el hombre es movido entre la representación y el asentimiento, un momento que no se encuentra cubierto en la tradicional clasificación estoica ${ }^{30}$. Dicha etapa intermedia -en general calificada como delectatio- representa en cierto sentido el momento central de la tentación. Abelardo conecta con esta tradición explícitamente, señalando que el pecado o la tentación pasan (peragi) por tres etapas: suggestio, delectatio y consensus. Está claro que Abelardo conoce la tradición exegética sobre la materia: "Hay que entender -escribe- que dirigiéndonos a obrar el pecado, frecuentemente somos conducidos por estas tres etapas, tal como ocurrió a nuestros primeros padres" "31. Pero él mismo procede a distribuir las funciones de modo tal que puede prescindir de Adán: la primera fase (persuasio) queda en manos del demonio, a lo cual sigue el deleite de la mujer (delectatio, concupiscentia), y finalmente el consentimiento dado por ella misma ${ }^{32}$. Lo que a continuación acentúa Abelardo, en consonancia con lo que conocemos de su programa, es el hecho de que la delectatio aún no constituye pecado, que sólo en el consensus pecamos.

¿De dónde sacó Abelardo este esquema y en qué sentidos puede ser iluminadora una comparación con Agustín? Son variadas las fuentes que puede haber tenido. La edición de Ilgner remite a algunos pasajes de Gregorio Magno e Isidoro de Sevilla, pero la deuda de Abelardo es mucho más clara para con un pasaje de Agustín al que tanto Ilgner como Luscombe remiten. Ahí, en el De sermone Domini in monte, la cuestión se plantea en los siguientes términos:

Tres son las etapas por las que llega a darse el pecado: tentación, deleite, consentimiento. [...] Si llega a haber consentimiento, es pleno el pecado, visible a Dios en nuestro corazón, aunque no sea notorio a los hombres mediante un acto. [...] Pero antes de que haya costumbre, el deleite es nulo, o tan tenue que es casi

30 Sobre este aspecto de la psicología estoica de la acción véase BOERI, M. Los Estoicos Antiguos. Traducción, Análisis y Notas Editorial Universitaria, Santiago de Chile, 2003. pp. 183-4. Como indica Boeri, hay en Séneca ep. 113, 18 y Cicerón De Fato 40 una excepción en cuanto al orden de los pasos. En estas dos excepciones hay una anticipación de lo que va a ser la tradicional tripartición en los autores cristianos.

31 ABELARDO. Scito te Ipsum I, 21, 3-4.

32 ABELARDO. Scito te Ipsum I, 21, 3-5. 
nulo; y sin embargo, es un gran pecado consentir a ese deleite, porque es ilícito. Cuando se ha consentido, se comete pecado en el corazón. Pero si además se procede al acto, parece saciarse y extinguirse el deseo. Pero después, cuando se repite la tentación, el deleite asciende a un mayor nivel, aunque todavía sea mucho menor al experimentado cuando por repetidos actos se adquiere una costumbre. Vencer a ésta, en efecto, es muy difícilis3.

Aquí estamos, me parece, ante el texto que más claramente se encuentra en el trasfondo de la discusión de Abelardo. Pues si bien hay una notoria afinidad conceptual de Abelardo con un texto del comentario antimaniqueo al Génesis en que Agustín también aborda el problema ${ }^{34}$, la afinidad terminológica es mayor con este pasaje, donde la segunda etapa es descrita como delectatio y no como cupiditas. Además, encontramos aquí un énfasis que Abelardo presenta más de una vez en conjunto con la tripartición: que Dios ve los corazones, donde se produce el consentimiento, que Él juzga de lo oculto, no de lo manifiesto como nosotros. De los textos que podrían haber servido de fuente a Abelardo, sólo éste vincula la tripartición con la distinción entre lo oculto y lo manifiesto. Ahora bien, si éste es el pasaje que Abelardo mejor conoce, vale la pena notar que en el texto en cuestión hay dos elementos que no hemos comentado, uno de los cuales acerca a Abelardo y Agustín y otro que los aleja. Lo que los acerca son las palabras finales sobre la dificultad de vencer. En efecto, las líneas que siguen en el texto citado de Agustín acentúan este punto introduciendo lenguaje militar: es posible vencer, escribe, si uno no deserta abandonando la militia christiana ${ }^{35}$. Esta concepción de la vida moral en gran medida como lucha es un tópico que atraviesa toda la ética de Abelardo: de la presencia de malas inclinaciones "obtenemos una gran materia -escribepara recibir la corona, triunfando sobre nosotros mismos mediante la virtud de la templanza"36. Pero junto a esto, como decía, Agustín introduce aquí un elemento que no se encuentra en Scito te Ipsum: el papel de la costumbre y las diferencias que en la lucha moral introduce el escenario creado por ella: el solo consentimiento, afirma Agustín, ya es pecado grave; pero la concreción del mismo en un acto externo lleva a la formación de hábitos, los cuales modifican el tipo de deleite que experimentamos, volviendo más firme la cadena que nos ata. Tenemos así una segunda vía por la que Agustín, en medio del énfasis puesto en el consentimiento interno, se abstiene de afirmar la indiferencia del acto externo. 
Para terminar, paso a considerar un texto en que esto se une a la gradación de los pecados. Podemos introducirlo preguntando qué tan nítida es la separación de las tres etapas del proceso. En un punto de su obra Abelardo concede que entre suggestio y delectatio el paso puede ser imperceptible: ver a una mujer hermosa puede de inmediato volverse un deleite pecaminoso en la visión de la misma ${ }^{37}$. Pero la fluidez que Abelardo pone entre esas dos etapas tiene por contraparte la radical separación que pone entre las dos etapas siguientes: le interesa afirmar que no importa cuánto sea el deleite, mientras que no haya consentimiento no hay pecado. Hasta aquí no hemos visto ninguna afirmación decisiva en Agustín, quien mantiene entre los tres pasos una separación bastante nítida, pero sin ignorar la retroalimentación entre éstos: tanto más frecuente sea el consentimiento, mayor será la tentación futura. Pero en De Trinitate XII, un texto de los más tardíos de su producción filosófica, la tripartición sufre una significativa transformación.

El cambio principal se encuentra en el hecho de que la razón, que es la que otorga el consentimiento, es ella misma subdividida en el De Trinitate. Ya no hay simplemente tentador externo para la suggestio, parte animal del hombre para la delectatio y luego la razón para la consensio, sino -de modo similar a Aristóteles (EN VI, 2)- dos partes de lo racional, una sabiduría primordialmente contemplativa y un saber práctico que en esta obra designa con el título de scientia. Como también en el De Trinitate estamos ante una explicación alegórica del Génesis, sigue habiendo papeles a repartir: Eva ya no representa un lado animal del hombre en el cual reside el deleite, sino que tiene que representar algo específicamente humano, aunque distinto de lo representado por Adán: así ella representa una razón inferior, práctica, y Adán la superior razón contemplativa, aunque, como veremos, también con componentes prácticos. ¿Qué ocurre con la tripartición de la tentación y caída tras esta bipartición de la razón? ¿Dónde queda el deleite si Eva ya no representa algo animal y dónde queda el consentimiento cuando hay dos partes racionales?

Lo que ocurre en De Trinitate XII es que el deleite sigue estando en Eva, pero por lo mismo ha cambiado la comprensión del tipo de deleite en cuestión. Hay deleite, pero no es un mero deleite animal, y hay también un consentimiento propio de esa razón inferior ${ }^{38}$. Agustín trabaja entonces aquí con dos tipos de consentimiento, conforme a los dos niveles de la razón que ha distinguido. Podría tras una tentación haber un deleite no culpable, en la 
medida en que no se le da el asentimiento. Pero dárselo también puede ocurrir a distintos niveles. Pues existe un consentir que no tiene intención alguna de desembocar en una obra externa. Es decir, no es que un impedimento externo impida la concreción de la obra, sino que se trata de consentir a seguir pensando en el pecado, deleitarse en la idea de cometerlo, dejar que resida en nuestra mente, pero sin intención alguna de materializarlo en un acto. Esto, desde luego, es pecado, pues ya implica consentimiento. Es un pecado que Agustín vincula expresamente con Eva, con la razón práctica. Con todo, es un pecado que, según afirmación de Agustín, más fácilmente puede alcanzar el perdón, precisamente haciendo lo que según Abelardo no nos traería perdón si se tratara de faltas graves: hay que pedir perdón y golpearse en el pecho ${ }^{39}$.

Pero, como ya indiqué, también en la sabiduría, representada por Adán, hay en la explicación de Agustín un componente práctico. En efecto, aquí se da otro tipo de consentimiento, que es el requerido para concretar una obra externa. La razón inferior, escribe Agustín, no puede ejecutar la obra "si aquella parte del espíritu que tiene la suma potestad para mover a la acción o refrenar respecto de ella no se rinde y sirve a la acción mala"40. La scientia sólo conduce a una obra externa consentiente sibi capite $s u{ }^{41}$, esto es, con la venia de la sabiduría, con la capitulación de la racionalidad rectora. Esta nueva explicación de Agustín tiene desde luego muchos aspectos que aquí no podemos comentar ${ }^{42}$, pero sí podemos usarla para volver sobre Abelardo. ¿Qué hubiese ocurrido si de todos los textos agustinianos sobre la tripartición de la tentación hubiese sido éste el usado por el Palatino? ¿Qué similitudes y semejanzas hay entre Abelardo y este Agustín? Una vez más, la cuestión permite sacar a la luz semejanzas y diferencias entre ambos. Las semejanzas pueden ser adecuadamente resumidas en torno al énfasis en lo interior: no sólo es cierto que en ambos autores es el consentimiento la condición necesaria y suficiente para que haya pecado, sino que este texto incluso nos ha presentado un caso en que Agustín vincula la gravedad del pecado al tipo de consentimiento dado. Pero precisamente ahí, en el modo en que Agustín trabaja con dos tipos distintos de consentimiento, se encuentra una gran diferencia entre ambos autores. ¿Qué gana Agustín con esta distinción? Ella le permite afirmar lo contrario de Abelardo: que con la comisión de la obra externa sí se acrecienta el mal. Pero la ampliamente difundida impresión de que la obra externa sí Journal (en prensa) y Theorie und Praxis bei Augustin. Eine Verhältnisbestimmung Freiburg: Alber, 2009. 
añade mal es algo que Agustín logra compartir no porque tenga la mente puesta en las consecuencias ni porque ponga menos énfasis en el acto interior que Abelardo, sino porque cree que para la comisión de una obra externa se requiere de una más profunda abdicación interior, de una expresa capitulación de la sabiduría.

\section{Conclusiones}

"El bien y el mal humano residen en la elección moral [prohairesis], y el resto de las cosas no son nada para nosotros" 43 . Tales palabras no provienen de un cristiano, sino que se encuentran en Epícteto. Esto significa que un énfasis tal en la disposición interior, que vuelve "nada" lo restante, proviene precisamente de aquella escuela filosófica de la Antigüedad para la que más central es la noción de ley natural, el estoicismo. Así se encuentra desde un comienzo unido lo que muchas veces se presenta como antagónico y como respectivamente representado por Abelardo y Agustín: las normas morales sin excepción y el énfasis en factores internos como los determinantes en la evaluación moral. Ahora bien, Abelardo y Agustín, contrariamente a lo que indica una vasta historia de recepción, no parecen diferir en relación a las normas morales carentes de excepción, pero sí en cuanto a la naturaleza del acto interior que resulta decisivo.

Una lectura atenta de dicha diferencia parece arrojar el siguiente resultado. $\mathrm{Si}$ trazamos una cadena del tipo suggestio-delectatio-consensio-opera, veremos a Abelardo poniendo algo de fluidez entre los dos primeros pasos, pero en lugar de eso poniendo fuertes saltos en el resto de las transiciones. Tales saltos se manifiestan en la indiferencia tanto de la delectatio como en la de la acción externa. Agustín, en cambio, no recurre en absoluto a la idea de indiferencia, y tiene una visión mucho más gradual de todos estos pasos. Si en Abelardo todo lo distinto del consentimiento es indiferente, en Agustín es más bien ambivalente. $Y$ tiene tres fuertes motivos para no considerar indiferente el acto externo: está preocupado de cómo por la caridad se "informa las costumbres", es consciente de que el acto externo genera hábitos que hacen más fuerte la próxima delectatio, y considera que para la realización de un acto externo es necesaria una más profunda abdicación interior que cuando sólo dejamos residir el pecado en nuestra mente mediante una forma más débil de consentimiento. Pero esto significa que la posición de Abelardo es descrita de 
un modo inadecuado si la reducimos a ser una "radicalización" de la posición de Agustín. Porque una radicalización sólo puede haber por un mismo camino, y los caminos de estos dos autores se apartan en puntos decisivos. Si se apartan, hay que elegir entre ambos. Y si es correcta la exposición que hemos hecho aquí, en tal elección la balanza debiera inclinarse a favor de Agustín: éste parece tener todas las ventajas de la posición de Abelardo pero sin sus problemas, y mediante la distinción entre scientia y sapientia ofrece además un análisis más diferenciado que su sucesor. 